\title{
Loss of Mtmr2 Phosphatase in Schwann Cells But Not in Motor Neurons Causes Charcot-Marie-Tooth Type 4B1 Neuropathy with Myelin Outfoldings
}

\author{
Annalisa Bolis, ${ }^{1}$ Silvia Coviello, ${ }^{1}$ Simona Bussini, ${ }^{1}$ Giorgia Dina, ${ }^{2}$ Celia Pardini, ${ }^{3}$ Stefano Carlo Previtali, ${ }^{2}$ \\ Mariachiara Malaguti, ${ }^{2}$ Paolo Morana, ${ }^{2}$ Ubaldo Del Carro, ${ }^{2}$ Maria Laura Feltri, ${ }^{3}$ Angelo Quattrini, ${ }^{2}$ Lawrence Wrabetz, ${ }^{3}$ \\ and Alessandra Bolino ${ }^{1}$ \\ ${ }^{1}$ Dulbecco Telethon Institute, ${ }^{2}$ Department of Neurology, and ${ }^{3}$ Department of Biological and Technological Research, San Raffaele Scientific Institute, 20132 \\ Milano, Italy
}

\begin{abstract}
Mutations in MTMR2, the myotubularin-related 2 gene, cause autosomal recessive Charcot-Marie-Tooth type 4B1 (CMT4B1). This disorder is characterized by childhood onset of weakness and sensory loss, severely decreased nerve conduction velocity, demyelination in the nerve with myelin outfoldings, and severe functional impairment of affected patients, mainly resulting from loss of myelinated fibers in the nerve. We recently generated Mtmr2-null ${ }^{\text {neo }}$ mice, which show a dysmyelinating neuropathy with myelin outfoldings, thus reproducing human CMT4B1. Mtmr2 is detected in both Schwann cells and neurons, in which it interacts with discs large 1/synapseassociated protein 97 and neurofilament light chain, respectively. Here, we specifically ablated Mtmr2 in either Schwann cells or motor neurons. Disruption of Mtmr2 in Schwann cells produced a dysmyelinating phenotype very similar to that of the Mtmr2-null ${ }^{\text {neo }}$ mouse. Disruption of Mtmr2 in motor neurons does not provoke myelin outfoldings nor axonal defects. We propose that loss of Mtmr2 in Schwann cells, but not in motor neurons, is both sufficient and necessary to cause CMT4B1 neuropathy. Thus, therapeutical approaches might be designed in the future to specifically deliver the Mtmr2 phospholipid phosphatase to Schwann cells in affected nerves.
\end{abstract}

Key words: neuropathy; myelin; phosphatase; mice; Schwann cell; motor neuron

\section{Introduction}

Myelin is a highly specialized structure of vertebrates formed by the plasma membrane of Schwann cells in the peripheral nervous system, which enwraps larger axons in a spiral manner. This structure allows faster propagation of action potentials because of saltatory conduction. In the "axon-Schwann cell unit," myelinforming Schwann cells affect axonal health and regulate clustering of channels at the node of Ranvier, axonal diameter, cytoskeleton, and transport (Jessen and Mirsky, 2004). Axons provide signals for Schwann cell survival, proliferation, differentiation, and myelination (Poliak and Peles, 2003; Salzer, 2003; Jessen and Mirsky, 2004; Trapp and Kidd, 2004). Only a few genes that mediate this reciprocal relationship have been identified (LappeSiefke et al., 2003; Michailov et al., 2004).

Received June 17, 2005; revised Aug. 1, 2005; accepted Aug. 5, 2005.

This study was supported by grants from Telethon, Italy (A. Bolino, S.C.P., M.L.F., and L.W.), the National Institutes of Health (M.L.F. and L.W.), Compagnia San Paolo (A. Bolino), and the Fondazione Mariani, Italy (L.W.). A. Bolino is a recipient of a Telethon Assistant Scientist Career Award. We acknowledge the kind collaboration of Silvia Arber (University of Basel, Basel, Switzerland) and Thomas Jessell (Columbia University, New York, NY), who provided the HB9-Cre transgenic mouse. We thank Marina Scarlato, Stefano Grassi, and Felipe Court (San Raffaele Scientific Institute, Milan, Italy) for their help. We also thank Elior Peles (The Weizmann Institute of Science, Rehovot, Israel) and Terunaga Nakagawa (Massachusetts Institute of Technology, Boston, MA) for antibodies.

Correspondence should be addressed to Dr. Alessandra Bolino, Dulbecco Telethon Institute, Department of Biological and Technological Research, San Raffaele Scientific Institute, Via Olgettina 58, 20132 Milano, Italy. E-mail: bolino.alessandra@hsr.it.

DOI:10.1523/JNEUROSCI.2493-05.2005

Copyright $\odot 2005$ Society for Neuroscience $\quad$ 0270-6474/05/258567-11\$15.00/0
Charcot-Marie-Tooth (CMT) disease represents a heterogeneous group of inherited disorders affecting myelinated axons in the peripheral nervous system (Suter and Scherer, 2003; Wrabetz et al., 2004). CMTs are characterized by progressive distal muscular atrophy and weakness with an age of onset between the first and second decades of life. Two main phenotypes have been classically recognized: primary demyelinating CMT type 1 (CMT1) with nerve conduction velocities (NCVs) $<38 \mathrm{~m} / \mathrm{s}$ and primary axonal CMT2 associated with normal values of NCV $(>38 \mathrm{~m} / \mathrm{s})$ and decreased compound motor action potential (CMAP). Because of the intimate relationship between Schwann cells and axons, axonal loss and/or atrophy might also occur as a consequence of primary demyelination and vice versa. Moreover, CMT forms with "intermediate" slowing of NCV between 25 and 45 $\mathrm{m} / \mathrm{s}$ have also been reported (Davis et al., 1978; Rouger et al., 1997). At least 22 responsible genes have been isolated thus far (http://www.molgen.ua.ac.be/CMTMutations/default.cfm). Although the pattern of expression of several CMT genes predicts phenotype (Schwann cell-specific with demyelinating, neuronspecific with axonal), for many CMT genes, it does not. For instance, mutations in $M P Z$, the myelin protein zero gene, which is specifically expressed in Schwann cells, are associated with primary demyelinating, axonal, and intermediate forms of CMT (Shy, 2004). The GDAP1 gene, the expression of which is highly enriched in neurons, is responsible for demyelinating, axonal, and intermediate CMTs (Pedrola et al., 2005). Other genes, al- 
though ubiquitously expressed in nerve, are specifically associated with primary axonal CMTs (e.g., MFN2, RAB7, HSP22/27, and GARS) (Antonellis et al., 2003; Verhoeven et al., 2003; Evgrafov et al., 2004; Irobi et al., 2004; Zuchner et al., 2004) or primary demyelinating CMTs [e.g., myotubularin-related 2 (MTMR2) and MTMR13] (Bolino et al., 2000; Azzedine et al., 2003; Senderek et al., 2003).

The MTMR2 and MTMR13 genes are responsible for the demyelinating autosomal recessive CMT type 4B1 (CMT4B1) and CMT4B2, respectively. CMT4B is a severe neuropathy characterized by childhood onset of weakness and sensory loss, severely decreased NCV, and, in the nerve, demyelination, loss of myelinated fibers, hypomyelination, and myelin outfoldings (Quattrone et al., 1996). MTMR2 and MTMR13 represent catalytically active and inactive phosphatase proteins, respectively, belonging to the myotubularin-related protein family, which comprises 14 members in human, named MTM1 and MTMR1-MTMR13 (Laporte et al., 2003). Although MTMRs share extensive homology with phosphotyrosine/dual-specificity phosphatases, they dephosphorylate phosphoinositides (Schaletzky et al., 2003).

We recently generated Mtmr2-null ${ }^{\text {neo }}$ mice, which recapitulate the CMT4B1 pathology (Bolino et al., 2004). These mutants develop a progressive neuropathy with myelin outfoldings and redundant loops of myelin originating mainly at paranodal regions and impaired spermatogenesis. However, this mouse model does not demonstrate whether loss of Mtmr2 in Schwann cell and/or neurons provokes the dysmyelination observed in the nerve. Moreover, a cell autonomous role for Mtmr2 in both Schwann cells and neurons might be predicted on the basis of expression as well as physical interactions. We recently showed that Mtmr2 is expressed in vivo in myelin-forming, non-myelinforming Schwann cells and axons. We also provided evidence that Mtmr2 might interact in neurons with neurofilament light chain (NF-L), a protein mutated in other forms of CMT (Previtali et al., 2003). In Schwann cells, Mtmr2 interacts with discs large 1 (Dlg1)/synapse-associated protein 97 (SAP97), which is enriched in the paranodal cytoplasm. In Mtmr2-null ${ }^{\text {neo }}$ nerves, the Mtmr2/Dlg1 complex is disrupted (Bolino et al., 2004). To gain insight into the function of Mtmr2 in Schwann cells and neurons, we specifically ablated Mtmr2 in either Schwann cells or motor neurons using the Cre/loxP technology. Here, we report that inactivation of Mtmr2 in Schwann cells and not in motor neurons is sufficient and necessary to produce CMT4B1 neuropathy with myelin outfoldings.

\section{Materials and Methods}

Generation of Mtmr2 conditional mutants. The generation of an Mtmr2 Floxed allele has been reported previously (Bolino et al., 2004). To produce mice with specific ablation of Mtmr2 in either Schwann cells or motor neurons, $M t m r 2 \mathrm{Fl}^{\text {neo }}$ (floxed with neo) mice were crossed with transgenics carrying the Flpe recombinase for excision of the neo cassette (see Fig. 1A). Homozygous Mtmr2Fl mice were then crossed with heterozygous $M t m r 2-$ null ${ }^{\text {neo }}$ mice (lacking exon 4 but still containing the neo cassette) carrying the P0-Cre or the HB9-Cre transgene. Mtmr2Fl/ null $^{\text {neo } / / P 0-C r e ~ o r ~ H B 9-C r e ~ m i c e ~ a r e ~ t h e ~ c o n d i t i o n a l ~ n u l l ~ i n ~ S c h w a n n ~}$ cells or in motor neurons, respectively. Homozygous Mtmr2Fl mice are normal, and no morphological alterations were observed in their nerves (data not shown). Congenic C57BL/6 mouse strains carrying the P0-Cre or HB9-Cre transgenes were used. Mice with conditional ablation of Mtmr2 were generated on a mixed C57BL/6/129SvPas genetic background ( $n=3$ or 4 ). All experiments involving animals were performed in accordance with Italian national regulations and covered by experimental protocols reviewed by local Institutional Animal Care and Use Committees.
PCR analysis. Genotype analysis of tail genomic DNA used primer pairs $\mathrm{C}$ and $\mathrm{B}$ or $\mathrm{A}$ and $\mathrm{D}$ to distinguish between the $(+/+)$ wild-type, $M t m r 2 \mathrm{Fl}^{\text {neo }}$, and $\mathrm{Mtmr2-null}{ }^{\text {neo }}$ mice as described previously (Bolino et al., 2004). Excision of the neo cassette from the floxed allele was assessed using primers D (designed as Forward) and E (see Fig. $1 A$ ). Finally, the conditional Mtmr2Fl/null ${ }^{\text {neo }} / / \mathrm{P} 0-C r e$ or HB9-Cre mice were genotyped using primers $\mathrm{C}$ and $\mathrm{B}$ and specific primers to $\mathrm{P} 0$-Cre or $\mathrm{HB} 9-\mathrm{Cre}$ transgenes. Genomic DNA extracted from several tissues was amplified using primers $\mathrm{A}$ and $\mathrm{E}$, which were able to amplify only the allele in which the neo cassette has been removed (Fl) (see Fig. $1 B, C$ ).

Dissection of motor neurons from the spinal cord was performed by laser capture microdissection according to the instructions of the manufacturer (LS LMD; Leica, Northvale, NJ). Genomic DNA was extracted using the QIAamp DNA Microkit (Qiagen, Germantown, MD), and PCR was performed using standard conditions with 45 cycles of amplification. The following pairs of primers were used: primers A and D for Mtmr2null $^{\text {neo }}$ mice (see Fig. $1 D$ ); primers A and E for Mtmr2Fl/null ${ }^{\text {neo } / / H B 9-~}$ Cre mice (see Fig. $1 D^{\prime}$ ). In this way, a product of amplification was detected in both cases confirming that genomic DNA was always obtained from laser-dissected cells.

cDNA synthesis on total RNA extracted from sciatic nerve, muscle, and brain was performed as described previously (Bolino et al., 2002). At least three animals per genotype were analyzed for brain and muscle. For sciatic nerve, three independent RNA pools of four nerves (two animals) were used in a single reaction to increase the amount of the RNA analyzed.

The expression of selected mRNAs was determined by real-time PCR (RT-PCR). Samples were processed in triplicate, and reactions without target cDNA were used as negative control for each reaction. PCRs were performed on 96-well plates using the TaqMan Universal Master Mix (Applied Biosystems, Foster City, CA) and following the conditions of the manufacturer. TaqMan probes (Applied Biosystems) were used to amplify mouse Mtmr2, Mtmr13, Mtm1, Mtmr5, and Mtmr12 (3phosphatase adapter protein) and the endogenous reference transcripts glyceraldehyde-3-phosphate dehydrogenase and PGK (phosphoglycerate kinase). RT-PCR efficiencies (E) of each transcript were first determined using at least eight different amounts of reverse-transcribed mRNA. To this aim, the comparative $C_{\mathrm{T}}$ method (ABI PRISM Sequence Detection System User Bulletin 2; Applied Biosystems) and the ABI PRISM 7700 Sequence Detection System (version 1.6 software) were used. When log input total RNA amounts were plotted versus $\Delta C_{\mathrm{T}}$ (selected transcript $C_{\mathrm{T}}$ minus endogenous reference $C_{\mathrm{T}}$ ), only slopes $<0.1$ were taken into account. As a calibrator, a control sample $\Delta C_{\mathrm{T}}$ was chosen for each selected transcript in each tissue. The $\Delta \Delta C_{\mathrm{T}}\left(\Delta C_{\mathrm{T}}\right.$ of each normalized selected transcript minus $\Delta C_{\mathrm{T}}$ of the calibrator) was calculated. Expression levels of each mRNA (the $2^{-\Delta \Delta \mathrm{CT}}$ values) are indicated as " $n$-folds" relative to 1 , which correspond to the $2^{-\Delta \Delta \mathrm{CT}}$ value of the calibrator.

For statistical analysis, the StatView program (version 5.0) with the paired $t$ test method was used. The SD was calculated for triplicate samples of each reaction, and SEM is indicated on the media of the determinations from different animals (see Fig. 9).

In situ hybridization analysis. A cDNA fragment of 500 bp containing exons 11-14 of Mtmr2 cDNA was amplified from mouse nerve total RNA and cloned into TA vector (Invitrogen, Carlsbad, CA). This product was then subcloned into pBluescript II KS- and used as a template to generate probes. The resulting plasmid was linearized by digestion with HindIII and transcribed with T7 RNA polymerase to obtain antisense probe and linearized with XhoI and transcribed with T3 RNA polymerase to obtain the sense probe. In situ hybridization experiments were performed as reported previously (Bulfone et al., 1993)

Behavioral analysis and electrophysiology. Rotarod test groups of mice 6 months of age were placed on a rotating cylinder that accelerated from 4 to 40 rotations per minute (rpm) over $5 \mathrm{~min}$ (Ugo Basile, Comerio, Italy). The animals were allowed to stay on the cylinder for a maximum of $700 \mathrm{~s}$, and the time to fail was measured in different trials (two trials of three replicates per day for $3 \mathrm{~d}$, nonconsecutively). For statistical analysis, the StatView program (version 5.0) with the paired $t$ test method was used. Electrophysiology was performed as described previously (Bolino et al., 2004). 
Morphological analysis. Three animals per genotype for each time point were analyzed. Semithin section analysis of sciatic, saphenous, quadriceps, and digital nerves was performed as reported previously (Wrabetz et al., 2000).

The proportion of fibers having outfoldings was counted as previously reported on at least 800-1000 fibers observed in three random microscopic fields from nerves of three animals. The proportion of fibers with more than three loops of redundant myelin was calculated as the percentage of fibers showing outfoldings. To perform morphometric analysis, digitalized images of fiber cross sections were obtained from corresponding levels of the sciatic or quadriceps nerves with a $100 \times$ objective and digital camera Leica DFC300F. At least three images from three different animals per genotype at 8 months of age were acquired $\left(120 \times 103 \mu \mathrm{m}^{2}\right.$ of sciatic nerve per each animal) and analyzed with the Leica QWin software (Leica Microsystem). The g-ratio was determined by dividing the mean diameter of an axon (without myelin) by the mean diameter of the same axon including myelin. Approximately 150 randomly chosen fibers per animal were analyzed. Myelinated axons in the first toe were counted in a cross section and the two plantar nerves (derived from sciatic nerve) were analyzed (Frei et al., 1999). Statistical analysis was performed using Statview 5.0 software (SAS Institute, Cary, NC). Ultrathin morphological analysis was performed as described previously (Wrabetz et al., 2000). Teased fiber preparation was performed as reported previously (Previtali et al., 2000).

Hematoxylin, eosin, and ATPase isozyme staining of posterior compartment muscles of the leg were performed as described previously (Wrabetz et al., 2000).

Antibodies. The following antibodies were used for immunohistochemistry: rabbit polyclonal anti-SAP97 (provided by Dr. T. Nakagawa, Massachusetts Institute of Technology, Boston, MA), rabbit polyclonal anti-Caspr-GOGI (provided by Dr. E. Peles, The Weizmann Institute of Science, Rehovot, Israel), mouse monoclonal anti-NaCh PAN (Sigma, St. Louis, MO), rabbit polyclonal anti-Kv1.1/1.2 (Alomone Labs, Jerusalem, Israel), mouse monoclonal anti-E-Cadh (Transduction-BD, Franklin Lakes, NJ), and mouse monoclonal anti-MAG (Chemicon, Temecula, CA). For Western blot analysis on sciatic nerve homogenates, performed as described previously, a mouse monoclonal anti-E-Cadh antibody (Transduction-BD) was used.

Secondary antibodies included fluorescein-conjugated (FITC) or rhodamine-conjugated (tetramethylrhodamine isothiocyanate) donkey anti-mouse or rabbit IgG-conjugated (Jackson ImmunoResearch, West Grove, PA) or peroxidase-conjugated goat anti-rabbit or rabbit antimouse IgG (Dako, Glostrup, Denmark).

Immunohistochemistry and confocal microscopy. Immunofluorescence on cryosections was performed as described previously (Previtali et al., 2003) and examined with confocal (Bio-Rad MRC 1024; Bio-Rad, Hercules, CA) or fluorescent (Olympus BX; Olympus Optical, Tokyo, Japan) microscopy. For immunohistochemistry, sciatic nerves were removed and rapidly snap-frozen in liquid nitrogen, either unfixed or previously fixed in buffered $4 \%$ paraformaldehyde. For teased fiber preparation, sciatic nerves were removed, fixed on ice in freshly prepared buffered $4 \%$ formaldehyde, as described by Bolino et al. (2004). The slides were washed in PBS and incubated with appropriate secondary antibodies (Jackson ImmunoResearch) and mounted with Vectashield (Vector Laboratories, Burlingame, CA). Quantification of the average of signal intensity was performed on fibers from at least two animals per genotype using the ImageJ program (version 1.32j; http://rsb.info.nih.gov/ij/). For MAG and Dlg1 staining, the average intensity of nonsaturated signals on images acquired with the same parameters between wild-type and mutant fibers was measured. The area corresponding to the Caspr staining in double-labeling experiments Dlg1/Caspr and MAG/Caspr was chosen. The average of signal intensity of the background (other regions without specific signals; e.g., internodes) was subtracted from the average of signal intensity of MAG and Dlg1. Measurements of NaCh cluster size were determined on $\mathrm{NaCh} / \mathrm{Caspr}$ double immunostaining and normalized using $\mathrm{NaCh}$ cluster diameter for each node. Caspr clusters distance and Caspr clusters length were measured on E-cadh/Caspr double immunostaining and normalized for Caspr diameter. Kv1.1/Kv1.2 cluster length and distance were measured on $\mathrm{NaCh}$ and $\mathrm{Kv1.1/Kv1.2} \mathrm{double} \mathrm{immu-}$ nostaining and normalized with the NaCh cluster diameter. For Kv1.1/ Kv1.2 cluster staining, fixed thresholds across all samples (upper and lower limits) of saturated signal intensity were chosen. Statistical analysis was performed using the StatView program (version 5.0) and the paired $t$ test method.

Image analysis. Micrographs were acquired using a digital camera (Leica F300), and figures were prepared using Adobe Photoshop version 8.0 (Adobe Systems, San Jose, CA).

\section{Results}

\section{Generation of a conditional targeted allele for tissue-specific ablation of $\mathrm{Mtmr2}$}

A Floxed ${ }^{\text {neo }}$ Mtmr2 allele was produced in which exon 4 was flanked by lox- $P$ sites in a pFlrt1 vector carrying a neo cassette between FRT sites (Bolino et al., 2004). Excision of exon 4 introduces a frameshift from both ATG start sites of translation (exon 1 and 3 ) and is predicted to code for a short truncated protein, lacking all functional domains of the protein (Fig. $1 A$ ). To produce mice with Mtmr2-specific ablation in either Schwann cells or motor neurons, we crossed homozygous Mtmr2Fl mice with heterozygous Mtmr2-null ${ }^{\text {neo }}$ mice carrying the P0-Cre or the HB9-Cre transgenes.

$\mathrm{P} 0$-Cre produces somatic recombination of floxed genes specifically in Schwann cells and not in dorsal root or spinal motor neurons that contribute axons to peripheral nerves (Feltri et al., 1999, 2002). To confirm Schwann cell-specific ablation in Mtmr2Fl/null ${ }^{\text {neo }} / / \mathrm{P} 0$-Cre mice, we performed a PCR assay on genomic DNA from nerve and other tissues, which demonstrated that exon 4 was nearly completely excised in the sciatic nerve (remaining non-recombined signal probably originates from perineurium), whereas there was no recombination signal in the spleen and liver. The faint recombination signal in muscle is attributable to the presence of nerves in this tissue (Fig. $1 B$ ). Recombination in a few cells in the brain mediated by P0-Cre has been reported for some loci (M. L. Feltri, unpublished results).

HB9-Cre produces somatic recombination at embryonic day 9.5 (E9.5) in motor neurons and the pancreas (Arber et al., 1999; Li et al., 1999; Yang et al., 2001). To show Mtmr2 motor neuronspecific ablation in $\mathrm{Mtm}$ r2Fl/null ${ }^{\text {neo }} / / \mathrm{HB} 9-\mathrm{Cre}$ mice, PCR analysis on genomic DNA was used to demonstrate no recombination signal in sciatic nerve (containing nuclei of Schwann cells but not of neurons), brain, liver, spleen, and muscle. Exon 4 was nearly completely excised in the pancreas and partially in the spinal cord, where other neuronal cell types and glial cells are located (Fig. 1C). To confirm motor neuron-specific ablation in the spinal cord, we selectively dissected motor neurons from spinal cord sections of $\mathrm{Mtmr} 2 \mathrm{Fl} / \mathrm{null}$ neo//HB9-Cre mice using laser-capture microdissection. A PCR assay was then performed on genomic DNA from laser-dissected cells and Mtmr2 ablation in motor neurons from both Mtmr2-null ${ }^{\text {neo }}$ mice (Fig. $1 D$ ) and Mtmr2Fl/null ${ }^{\text {neo }} / / \mathrm{HB} 9-C r e$ mice (Fig. 1D') was confirmed. Finally, by in situ hybridization analysis, we detected Mtmr $2 \mathrm{mRNA}$ in the spinal cord and specifically in ventral horn motor neurons of $\mathrm{Mtmr} 2 \mathrm{Fl} /$ null $^{\text {neo }} / / \mathrm{P} 0$-Cre mice, at levels similar to wild-type and not in $\mathrm{Mtmr} 2 \mathrm{Fl} / \mathrm{null}^{\text {neo }} / / \mathrm{HB} 9-\mathrm{Cre}$ or Mtmr2-null ${ }^{\text {neo }}$ motor neurons (Fig. 1E). Thus, Mtmr2 was completely and specifically ablated in either Schwann cells or motor neurons in the two conditional mutants.

\section{Mtmr2 disruption in Schwann cells is sufficient to provoke dysmyelination with myelin outfoldings}

Mtmr2Fl/null ${ }^{\text {neo }} / / \mathrm{P} 0$-Cre mice are viable and born according to the expected ratio. At external examination, no signs of tremor or functional disability were observed. Mutant and normal littermates showed comparable weights at the different time points, 
A
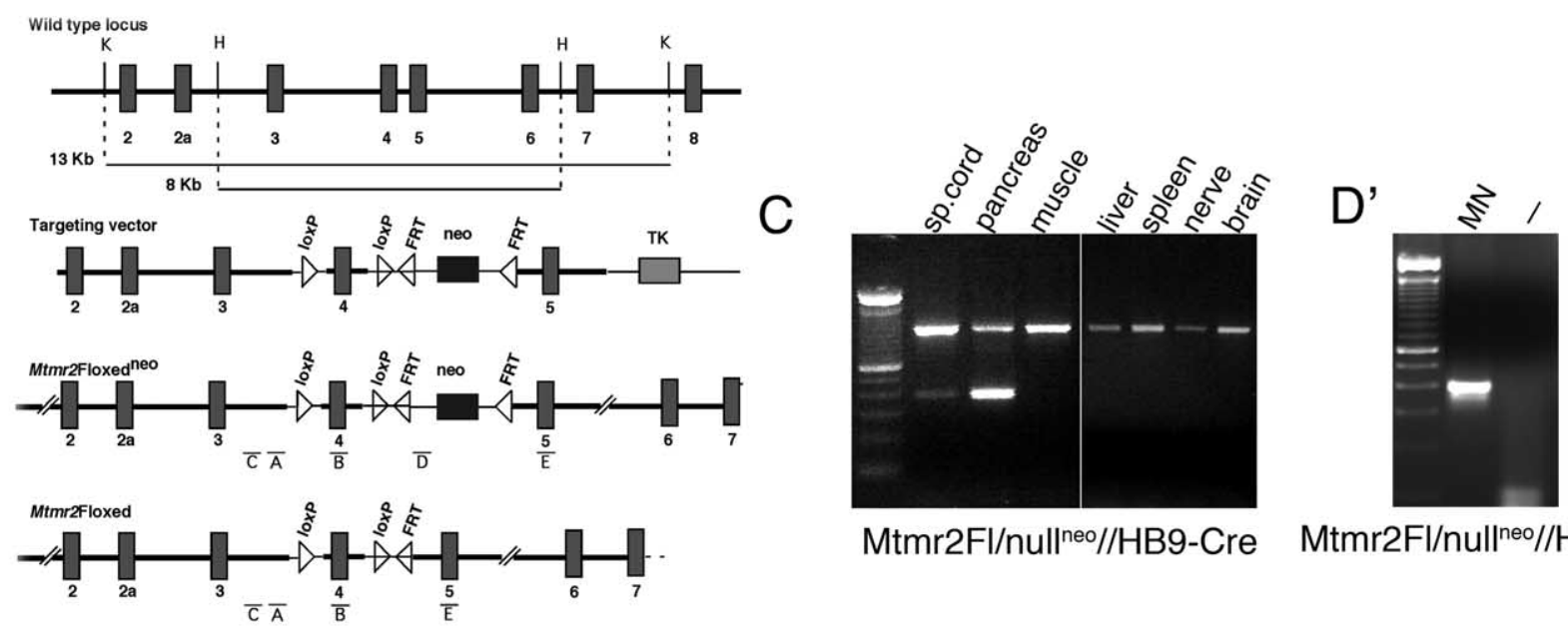

Mtmr2Fl/nullneo//HB9-Cre Mtmr2Fl/nullneo//HB9-Cre
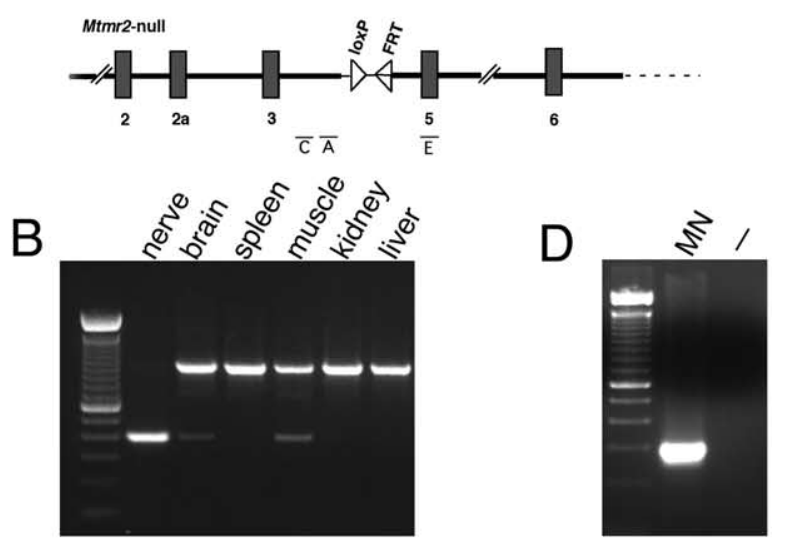

E
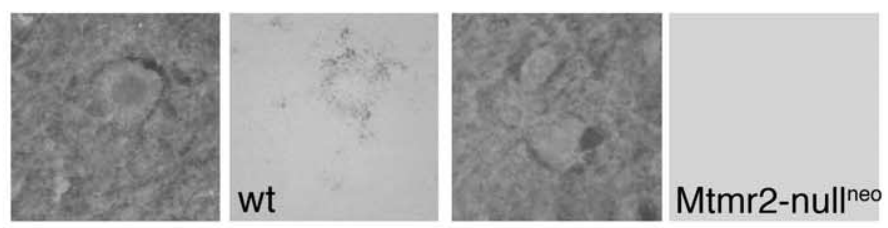

Mtmr2Fl/nullneo//PO-Cre

Mtmr2-nullneo
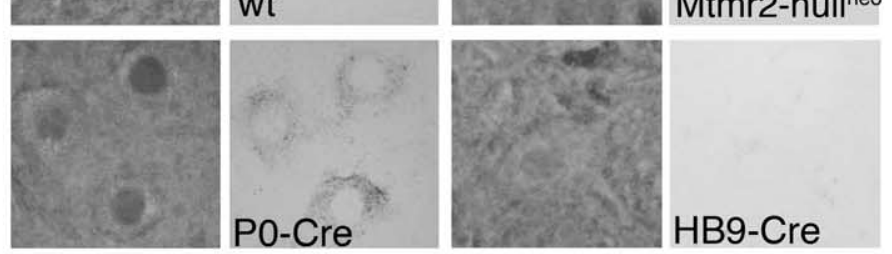

Figure 1. Generation of mice with Mtmr2 conditional ablation. $A$, First row, Genomic structure of Mtmr2 encompassing exon 4 (the wild-type Mtmr2 locus). Second row, Targeting construct in which Mtmr2 genomic fragments are represented by thick lines and vector sequences are represented by thin lines (the targeting vector). Third row, Mtmr2 locus after homologous recombination in ES cells as reported by Bolino et al. (2004) (the Mtmr2Fl ${ }^{\text {neo }}$ allele). Fourth row, Targeted allele without the neo cassette, removed in vivo using the Flpe transgene (the Mtmr2Fl allele). Fifth row, Targeted allele without neo and exon 4 (the Mtmr2-null allele). FRT, Flp recognition target; $\mathrm{H}$, Hindlll; $\mathrm{K}, \mathrm{Kpnl}$; TK, thymidine kinase gene. $\boldsymbol{B}$, PCR on genomic DNA from different tissues of

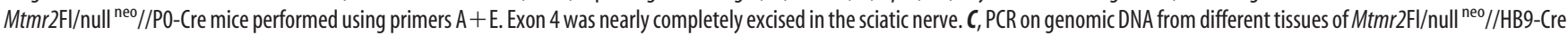
mice performed using primers $A+E$. Exon 4 was nearly completely excised in the pancreas (as shown in previous studies) and only partially in the spinal cord (sp. cord), in which other neuronal cell types, endothelial and glial cells, are located. No recombination was noted in other tissues. $D$, PCR on genomic DNA from laser capture-microdissected motor neurons (MN) of $M t m r 2-$-null ${ }^{\text {neo }}$ mice. The primer pair A+D was used. In these mice, exon 4 was removed from both Mtmr2-targeted alleles in which the neo cassette is still present. $D^{\prime}$, PCR on genomic DNA from laser capturemicrodissected motor neurons (MN) of Mtmr2F//null ${ }^{\text {neo }} / / \mathrm{HB} 9$-Cre mice. The primer pair A + E was used. In these mice, exon 4 was absent in motor neurons from the spinal cord (MN), and a band of $\sim 300$ bp was detected. If exon 4 was present, a band of $\sim 800 \mathrm{bp}$ (containing exon 4 and one lox $P$ site) would have been amplified, as in the case of the non-recombined tissues in $\boldsymbol{B}$ and $\boldsymbol{C}$. Empty lanes ( - in $\boldsymbol{D}$ and $\boldsymbol{D}^{\prime}$ correspond to the negative control of the PCRs. $\boldsymbol{E}$, In situ mRNA hybridization analysis using, as a probe, a portion of the Mtmr2 cDNA-containing exons 11-14. Mtmr2 mRNA is detected in motor neurons from wild-type (wt) and Mtmr2F//null ${ }^{\text {neo }} / / \mathrm{PO}$-Cre mice but not in Mtmr2Fl/null ${ }^{\text {neo }} / / \mathrm{HBg}$-Cre or Mtmr2-null ${ }^{\text {neo }}$ motor neurons.

different to what was observed in Mtmr2-null ${ }^{\text {neo }}$ mice (Bolino et al., 2004). Rotarod tests were therefore performed by placing 6-month-old mice on a horizontal cylinder rotating at increasing speed, and the time that they remain on the cylinder was measured in six different tests. Mutant animals remained on the cylinder significantly less than wild-type littermates, suggesting a neuromuscular defect in $\mathrm{Mtmr} 2 \mathrm{Fl} / \mathrm{null}^{\text {neo }} / / \mathrm{PO}$-Cre mice (Fig. $2 A)$. Electrophysiological examination of these mutants at 6 months of age revealed a significant reduction of nerve conduction velocities and prolonged F-wave latencies (Fig. 2B). Similar results have been obtained on $M t m r 2$-null ${ }^{\text {neo }}$ mice, as reported previously (Bolino et al., 2004). The amplitudes of proximal and distal compound motor action potentials were normal. At 12 months, no additional changes in nerve conduction velocities were observed in $M t m r 2 \mathrm{Fl} /$ null $^{\text {neo }} / / \mathrm{P} 0$-Cre mutants (Fig. $2 C$ ).

Myelin outfoldings were noted in nerves of $\mathrm{Mtmr} 2 \mathrm{Fl} /$ null $^{\text {neo } / /}$ P0-Cre mice with similar shape and number as seen in Mtmr2- null $^{\text {neo }}$ mouse nerves at $3-4$ weeks after birth (Fig. $3 A-F$ ). The number of fibers showing myelin outfoldings and redundant loops increases with age (in transverse semithin sections, $5 \%$ of myelinated fibers at 2 months, $10 \%$ at 4 months, $16 \%$ at 6 months, and $26 \%$ at 12 months). The complexity of the dysmyelinating morphology also increased with age as the number of fibers showing three or more satellite loops increased from 7.5\% at 2 months, $11.8 \%$ at 6 months, and up to $21.7 \%$ at 12 months of age. Remyelinated axons were observed at 12 and 15 months of age (Fig. $3 C, D)$. Occasional axonal degeneration was also noted in sciatic nerves of these mutants. A reduction of $33 \%$ of myelinated axons was noted in plantar nerves of the first toe examined at 12 months of age (Fig. 3E,F).

Longitudinal semithin sections of sciatic nerves showed that redundant loops of myelin arise not only at paranodal/juxtaparanodal myelin but also at Schmidt-Lanterman incisures (Fig. $3 G, H)$. By electron microscopy, the node of Ranvier, paranodal 


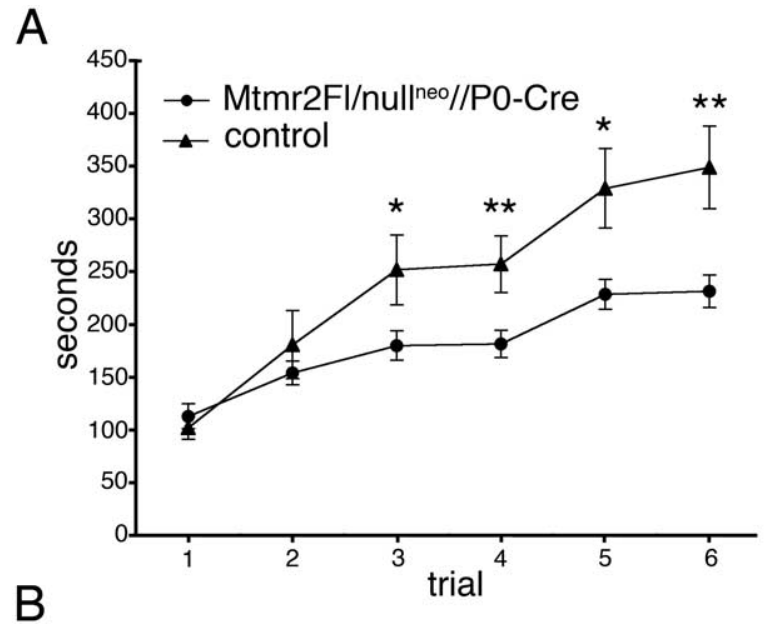

\begin{tabular}{|c|c|c|c|}
\hline & $\mathrm{Fl} /$ null| & control & \\
\hline NCV & $30.52 \pm 0.56 \mathrm{~m} / \mathrm{s}(11)$ & $37.01 \pm 1.01 \mathrm{~m} / \mathrm{s}(10)$ & $p<<0.001$ \\
\hline F-wave & $5.27 \pm 0.12 \mathrm{~ms}(11)$ & $4.80 \pm 0.10 \mathrm{~ms}(10)$ & $p<0.01$ \\
\hline
\end{tabular}

C

\begin{tabular}{|l|c|c|c|}
\hline & $\mathrm{Fl} /$ null & \\
\hline $\mathrm{NCV} / / \mathrm{PO}-\mathrm{Cre}$ & control & \\
\hline F-wave & $31.50 \pm 1.30 \mathrm{~m} / \mathrm{s}(8)$ & $41.88 \pm 1.26 \mathrm{~m} / \mathrm{s}(8)$ & $\mathrm{p}<<0.001$ \\
\hline
\end{tabular}

Figure 2. Behavioral and electrophysiological analysis of $M t m r 2 F / / n u l l ~{ }^{\text {neo }} / / \mathrm{PO}$-Cre mice. $A$, Rotarod test analysis performed on mutant and control animals at 6 months of age. For statistical analysis, the StatView program (version 5.0) with the paired $t$ test method was used. ${ }^{*} p<$ 0.05 ; ${ }^{* *} p<0.01$. B Electrophysiological analysis of $\mathrm{Mtmr} 2 \mathrm{Fl} /$ null $^{\text {neo }} / / \mathrm{PO}$-Cre mice and controls at 6 months of age. Reduction of NCV and prolonged F-wave latencies in mutant mice are comparable with those obtained for Mtmr2-null ${ }^{\text {neo }}$ mice at the same age, as reported by Bolino et al. (2004). C, Electrophysiological analysis of Mtmr2Fl/null ${ }^{\text {neo } / / P O-C r e ~ m i c e ~ a n d ~ c o n t r o l s ~ a t ~}$ 12 months of age.

loops, and axo-glial junctions between paranodal loops of Schwann cell membrane and axolemma appeared normal (Fig. $3 I, J)$. At Schmidt-Lanterman incisures evaginations contain both Schwann cell cytoplasm and axoplasm, contiguous with the main myelinated fiber (Fig. $3 K, L$ ).

\section{Dysmyelinating neuropathies in $\mathrm{Mtmr} 2 \mathrm{Fl} / \mathrm{null}^{\mathrm{neo}} / / \mathrm{P0}-\mathrm{Cre}$ and $M t m r 2-$ null $^{\text {neo }}$ mice are similar}

Electrophysiological and morphological analyses were performed on Mtmr2-null ${ }^{\text {neo }}$ mice until 6 months of age. This mutant showed a dysmyelinating phenotype with myelin outfoldings similar to those observed in $\mathrm{Mtmr} 2 \mathrm{Fl} / \mathrm{null}^{\text {neo }} / / \mathrm{P} 0$-Cre mice (Bolino et al., 2004). To compare further the neuropathy in the two mutants, Mtmr2-null ${ }^{\text {neo }}$ mice were also examined at 12 and 15 months of age. At 12 months, Mtmr2-null ${ }^{\text {neo }}$ mice showed reduced nerve conduction velocities [30.90 $\pm 1.59 \mathrm{~m} / \mathrm{s}(n=5)$ vs $38 \pm 2.52 \mathrm{~m} / \mathrm{s}(n=5) ; p<0.05]$ and prolonged F-wave latencies [5.06 $\pm 0.25 \mathrm{~ms}(n=5)$ vs $4.50 \pm 0.11 \mathrm{~ms}(n=5) ; p<0.05]$. These values are very similar to those obtained with Mtmr2Fl/ null $^{\text {neo } / / P 0-C r e ~ m i c e ~ a t ~ t h e ~ s a m e ~ a g e ~(c o m p a r e ~ w i t h ~ F i g . ~} 2$ B). The number of fibers with myelin outfoldings increases up to $20 \%$ at 15 months of age in complete null mice. The nerve morphology and shape of myelin outfoldings became more complex with age as shown in Figure $4 A-D$ at 12-15 months of age. Signs of axonal degeneration or de-remyelination were occasionally noted (Fig.

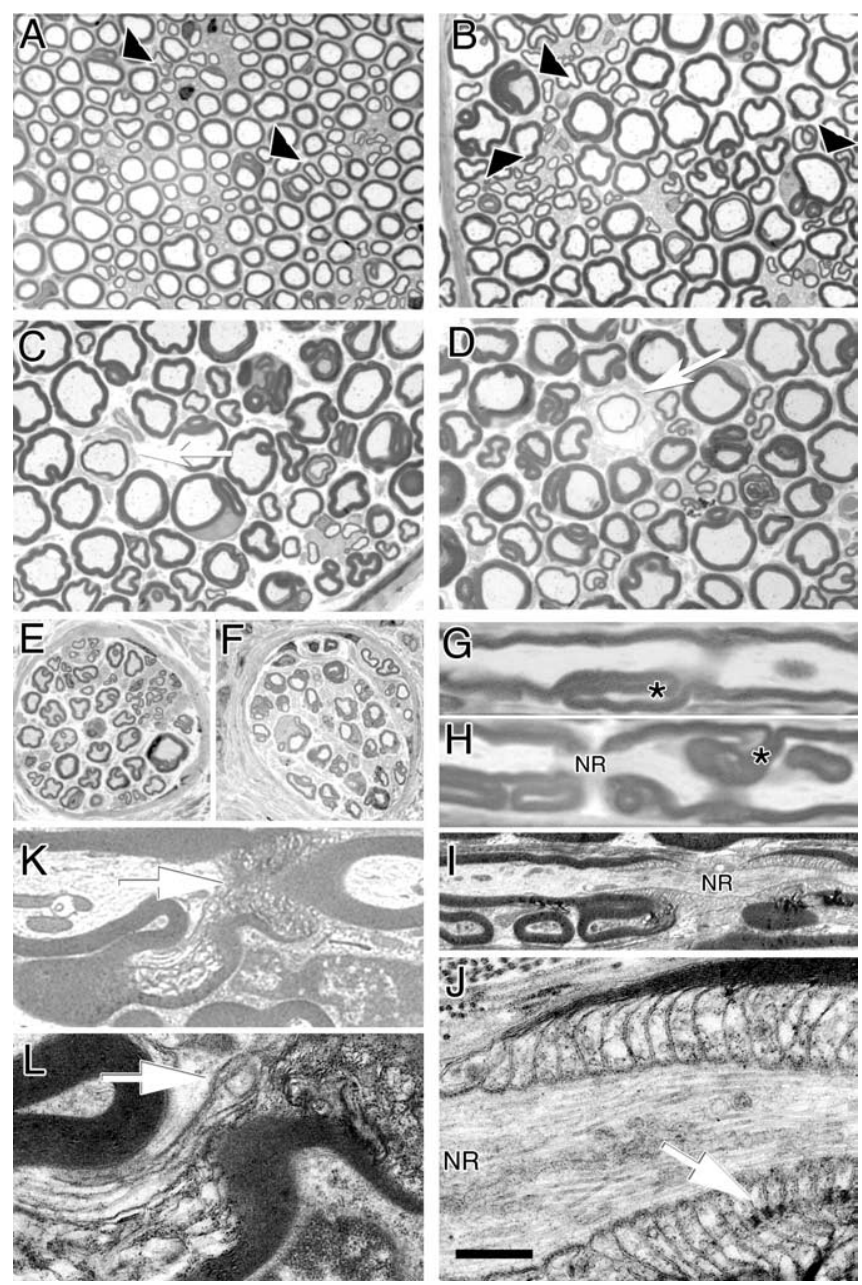

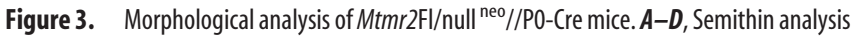
of sciatic nerves from mutant mice in a transverse section at 7 weeks and at 6,12 , and 15 months. Arrowheads indicate myelin outfoldings and redundant loops. Arrows indicate remyelinated axons at older ages. $\boldsymbol{E}, \boldsymbol{F}$, Digital nerves (plantar) from normal $(\boldsymbol{E})$ and mutant $(\boldsymbol{F})$ mice at 12 months of age. $\boldsymbol{G}, \boldsymbol{H}$, Semithin analysis of sciatic nerves in a longitudinal section at 12 months of age. Myelin infoldings $(\boldsymbol{H})$ and outfoldings $(\boldsymbol{G})$, which arise at $S$ chmidt-Lanterman incisures, are indicated by an asterisk. $\boldsymbol{H}$, Myelin outfoldings also arise at paranodal regions. NR, Node of Ranvier. I, J, Electron microscopy of a sciatic nerve analyzed at 12 months of age showing myelin outfoldings at paranodal regions $(I)$, which appeared normal with axo-glial junctions and adherens junctions in register (arrow) ( $\boldsymbol{J}$, enlarged). $\boldsymbol{K}, \boldsymbol{L}$, Electron microscopy showing myelin outfoldings at Schmidt-Lanterman incisures (arrows), enlarged in $L$. In the outfold, beneath the compact myelin sheath, Schwann cell cytoplasm containing vesicles and axoplasm contiguous with the main myelinated axon might be observed. Scale bar: $\mathbf{A}-\boldsymbol{F}, 25$ $\mu \mathrm{m} ; \boldsymbol{G}, \boldsymbol{H}, 6 \mu \mathrm{m} ; \boldsymbol{I}, 2 \mu \mathrm{m} ; \boldsymbol{J}, 400 \mathrm{~nm} ; \boldsymbol{K}, 3.5 \mu \mathrm{m} ; \boldsymbol{L}, 1.5 \mu \mathrm{m}$.

$4 E)$. Reduction of the number of myelinated axons was also observed in these mutants at 12 months of age in distal nerves such as plantar nerves of the first toe (data not shown). Teased fiber analysis as well as longitudinal semithin section of sciatic nerves at 6 and 12 months of age, respectively, demonstrated that redundant loops of myelin arise at Schmidt-Lanterman incisures in addition to paranodal/juxtaparanodal regions, as observed in

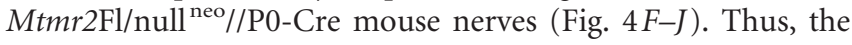
dysmyelinating neuropathy of $\mathrm{Mtmr2}$-null ${ }^{\text {neo }}$ mice is very similar to that of $M t m r 2 \mathrm{Fl} /$ null ${ }^{\text {neo }} / / \mathrm{P} 0$-Cre mice, with $M t m r 2$-specific ablation in Schwann cells.

\section{Disruption of Mtmr2 in motor neurons}

To assess whether axons contribute to the CMT4B1 pathology and whether Mtmr2 has a cell-autonomous role in neurons, we 


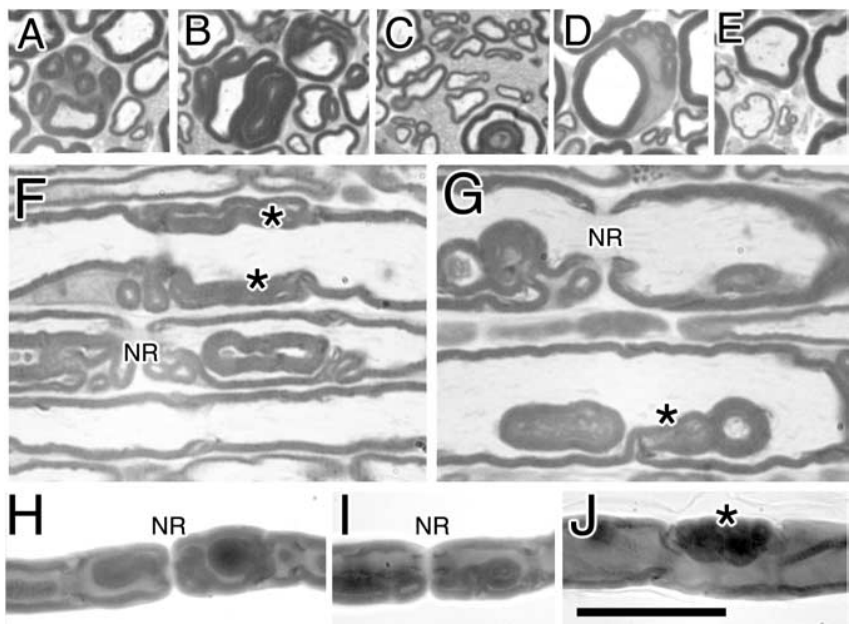

Figure 4. Morphological analysis of $M t m r 2-$-null ${ }^{\text {neo }}$ mice at 12 and 15 months of age. $\boldsymbol{A}-\boldsymbol{E}$, Different shape of myelin outfoldings in Mtmr2-null ${ }^{\text {neo }}$ mouse sciatic nerves at older ages when the complexity of the dysmyelinating phenotype progresses. In $A$ and $D$, up to five satellite loops are noted around a main myelinated fiber, which also appear around the nucleus (D). C, Myelin outfoldings in small caliber-myelinated fibers are shown. $\boldsymbol{E}$, A thin myelinated fiber is depicted. $F, G$, Semithin analysis in a longitudinal section of mutant sciatic nerves at 12 months of age. Asterisks indicate myelin loops arising at Schmidt-Lanterman incisures. $\boldsymbol{H}$-J, Teased fiber analysis of $M t m r 2-$ null ${ }^{\text {neo }}$ sciatic nerves at 6 months of age. Myelin outfoldings originate at paranodal regions but also at Schmidt-Lanterman incisures (asterisk). NR, Node of Ranvier. Scale bar: (in J) $\boldsymbol{A}-\boldsymbol{E}, 30 \mu \mathrm{m} ; \boldsymbol{F}-J, 8 \mu \mathrm{m}$.

also generated mice with Mtmr2-specific inactivation in motor neurons.

Mtmr2Fl/null ${ }^{\text {neo }} / / \mathrm{HB} 9-C r e$ mice are viable and born according to the expected ratio. Mutant and normal littermates showed comparable weights at the different time points. No signs of tremor or functional disability were observed on these mutants examined at different ages. Rotarod tests performed at 6 months of age did not reveal any significant difference between mutant and control mice (Fig. 5A). Accordingly, no alterations in the motor nerve conduction velocity and F-wave latency, which represent electrophysiological properties of motor axons, were demonstrated in $\mathrm{Mtmr} 2 \mathrm{Fl} /$ null $^{\text {neo }} / / \mathrm{HB} 9-\mathrm{Cre}$ mice at 6 months of age (Fig. $5 B$ ). Transverse semithin section analysis of sciatic, quadriceps, saphenous, and digital nerves were performed at different time points (1, 2, 4, 6, 8, and 12 months). Myelin outfoldings and infoldings were not demonstrated in nerves of these mutants (Fig. 6A-I). No signs of axonal degeneration were observed. The number of myelinated axons in plantar nerves of the first toe was similar to that of controls ( $\sim 80$ fibers in two plantar nerves). A morphometric analysis was performed on sciatic and quadriceps nerves of mutant mice and controls at 8 months of age. No differences in the axonal diameter and g-ratio were noted in either sciatic or quadriceps nerves (data not shown). Myelin structure also appeared normal when observed by electron microscopy (Fig. 6L,M). Moreover, no axonal swelling or any evident alteration in the axoplasm was noted. In peripheral neuropathies, loss of peripheral nerve fibers causes a rearrangement of the target muscle, including atrophic angulated fibers and, eventually, type grouping, resulting from degenerative-regenerative processes and collateral sprouting. No atrophic fibers and fiber-type grouping were noted in quadriceps muscle samples from mutant mice (Fig. 6J,K). In conclusion, $M t m r 2 \mathrm{Fl} /$ null $^{\text {neo }} / / \mathrm{HB} 9-C r e$ mice do not show either dysmyelination or axonopathy.

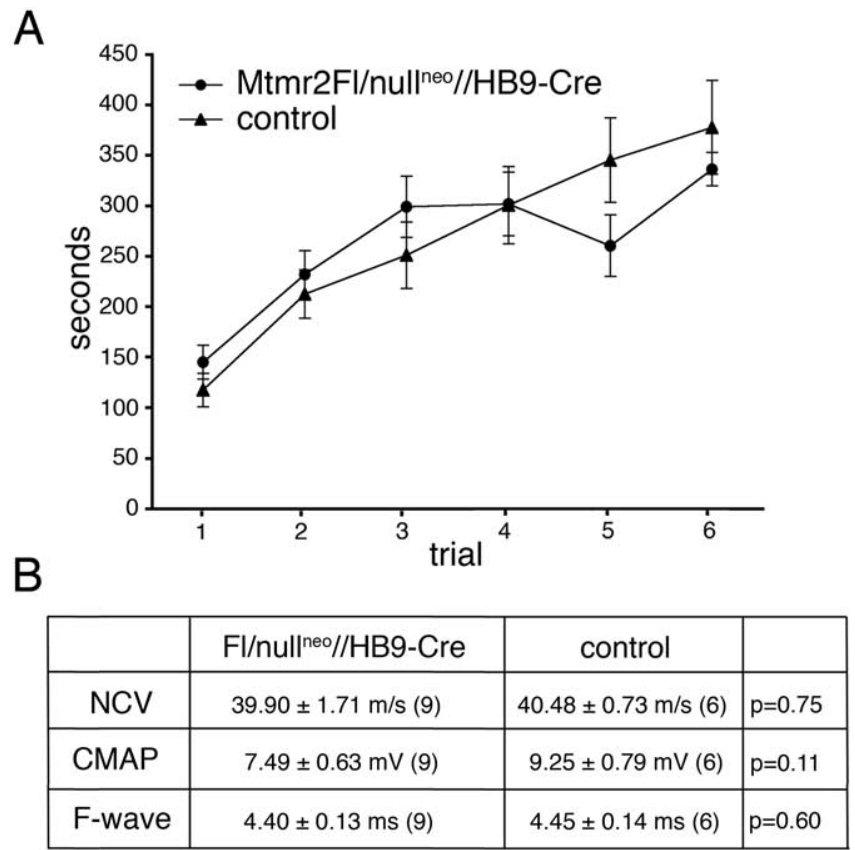

Figure 5. Behavioral and electrophysiological analysis of $\mathrm{Mtmr} 2 \mathrm{Fl} /$ null $^{\text {neo }} / / \mathrm{HB} 9-$-Cre mice. $A$, Rotarod test analysis performed on mutant and control animals at 6 months of age. No significant differences were observed in motor performances using the accelerating rod method. $\boldsymbol{B}$, Electrophysiological analysis of $M t m r 2 \mathrm{FI} /$ null ${ }^{\text {neo }} / / \mathrm{HB}$-Cre mice and controls at 6 months of age. NCV, F-wave latencies, and CMAP registered in mutant animals were similar to controls.

\section{Loss of Mtmr2 is associated with defects in non-compact myelin}

Inactivation of Mtmr2 in Schwann cells and not in motor neurons causes myelin outfoldings and redundant loops of myelin, which arise at regions of non-compact myelin such as paranodal/ juxtaparanodal regions and Schmidt-Lanterman incisures in both Mtmr2-null and Mtmr2Fl/null ${ }^{\text {neo } / / P 0-C r e ~ m o u s e ~ n e r v e s . ~}$ Western blot analysis on sciatic nerve homogenates from Mtmr2null $^{\text {neo }}$ mice demonstrated decreased levels of both MAG and Dlg1, an interactor of Mtmr2 in Schwann cells located at regions of non-compact myelin (Bolino et al., 2004). To evaluate the distribution of these molecules on normal and Mtmr2-null ${ }^{\text {neo }}$ nerves, we performed immunohistochemistry on mouse teased fibers. Dlg1 stains cytoplasm at paranodal regions of Schwann cells as well as flanking incisures (Fig. $7 A-A^{\prime}$ "). In Mtmr2-null ${ }^{\text {neo }}$ nerves, a faint Dlg1 signal was still detected at paranodes, whereas it was completely absent from flanking incisures (Fig. $7 B-B$ ”). Consistent with this, the Dlg1 average staining intensity at paranodes of control fibers was $58.1 \pm 3.7 \mathrm{pixel} / \mu \mathrm{m}^{2}$, whereas in mutant fibers, it was $10.2 \pm 1.7 \mathrm{pixel} / \mu \mathrm{m}^{2}(p<0.0001)$. MAG was properly distributed at incisures, ad-axonal Schwann cell membrane, and paranodal loops of Mtmr2-null ${ }^{\text {neo }}$ fibers (Fig. $7 C-C$ " $D-D$ "). However, staining intensity at paranodal loops appeared to be reduced in mutant nerves compared with controls (Fig. 7D-D"). Quantification of MAG immunostaining demonstrated that the average of the staining intensity at paranodes was $45.3 \pm 2.7 \mathrm{pixel} / \mu \mathrm{m}^{2}$ in control fibers and $19.7 \pm 1.6 \mathrm{pixel} / \mu \mathrm{m}^{2}$ in mutant nerves $(p<0.0001)$.

Myelin outfoldings arise at paranodal regions and at SchmidtLanterman incisures in Mtmr2-null ${ }^{\text {neo }}$ nerves. Electron microscopy performed on Mtmr2-null ${ }^{\text {neo }}$ fibers demonstrated that both electron-dense adherens junctions between loops of Schwann cell membrane as well as axo-glial junctions between Schwann cell 

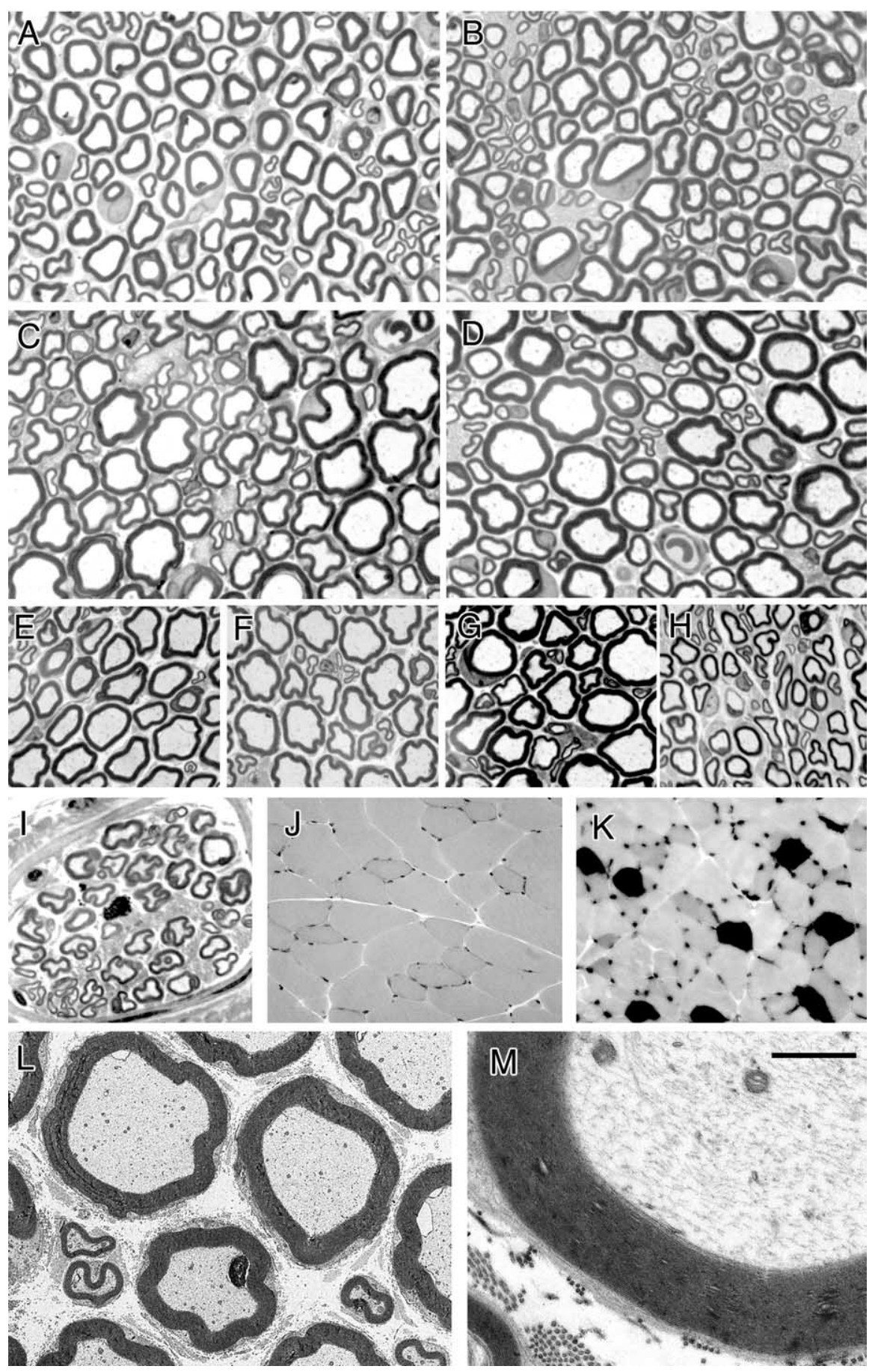

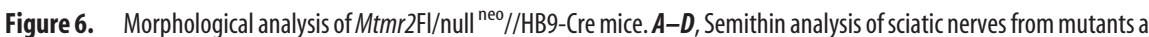
1 month $(\boldsymbol{A}), 2$ months $(\boldsymbol{B}), 6$ months $(\boldsymbol{C})$, and 12 months $(\boldsymbol{D})$ of age. No myelin outfoldings were noted. $\boldsymbol{E}-\boldsymbol{G}$, Quadriceps nerves from mutant mice at 5 months $(\boldsymbol{E}), 8$ months $(\boldsymbol{F})$, and 12 months $(\boldsymbol{G})$ of age and a saphenous nerve at 5 months of age $(\boldsymbol{H})$ in which no myelin outfoldings were observed. $I$, Digital nerve at 12 months without signs of dysmyelination (plantar nerve with $\sim 40$ myelinated fibers). $\boldsymbol{J}, \boldsymbol{K}$, ATPase isozyme staining of posterior compartment muscles of the leg shows that no type grouping occurred. $L, M$, Electron microscopy of quadriceps nerves at 12 months of age in which compact-myelin structure appears normal, and no axonal swelling was noted in the axoplasm. Scale bar: (in $\boldsymbol{M}$ ) $\boldsymbol{A}-\boldsymbol{I}, 25 \mu \mathrm{m} ; \boldsymbol{J}, \boldsymbol{K}, 80 \mu \mathrm{m} ; \boldsymbol{L}, 8 \mu \mathrm{m} ; \boldsymbol{M}, 3.5 \mu \mathrm{m}$.

junctions in Schwann cells (Fannon et al., 1995) and of Caspr (Paranodin)demarcating axo-glial junctions on the axolemma. Normal E-cadherin expression in Mtmr2-null ${ }^{\text {neo }}$ nerves was detected at Schmidt-Lanterman incisures, mesaxons, and as a more punctuate staining at paranodal loops of Schwann cells (Fig. 7E$E$ ", F-F"). A normal level of E-cadherin expression was further confirmed by Western blot analysis on sciatic nerve homogenates (data not shown). No difference in number and staining intensity of Caspr clusters was detected between mutant and normal teased fibers. No dispersion of Caspr clusters into the nodal region was noted (Fig. 7, compare $C^{\prime}$ and $D^{\prime}$, $E^{\prime}$ and $F^{\prime}, G^{\prime}$ and $H^{\prime}$ ).

Although the architecture of nodal and paranodal regions appeared normal in Mtmr2-null ${ }^{\text {neo }}$ nerves, a significant decrease in nerve conduction velocity $(\sim 19 \%)$ was demonstrated in both Mtmr2-null ${ }^{\text {neo }}$ and $\mathrm{Mtmr} 2 \mathrm{Fl} /$ null $^{\text {neo }} / / \mathrm{P0}$ Cre mutants. To assess whether this reduction might be related to the alteration of the number and/or distribution of $\mathrm{NaCh}$ and/or Kv1.1/Kv1.2 channel clusters, an expression analysis of $\mathrm{NaCh}$ and Kv1.1/Kv1.2 clusters was also performed. No difference in the number and staining intensity of $\mathrm{NaCh}$ and $\mathrm{Kv1} 1 / \mathrm{Kv} 1.2$ clusters was noted between mutant and normal fibers. NaCh clusters appeared normally distributed in the nodal region (Fig. $7 G-G$ ", $\left.H-H^{\prime \prime}\right)$. Kv1.1/Kv1.2 cluster staining was also properly detected at juxtaparanodal regions, and no dispersion throughout the internode was observed (Fig. 7I-I",J-J"). Consistently, NaCh cluster size, Caspr cluster distance, Caspr cluster length, Kv1.1/Kv1.2 cluster length, and Kv1.1/Kv1.2 cluster distance showed similar values between normal and mutant fibers (Fig. 8).

Expression analysis of members of the MTMR family

Overall, the neuropathy observed in both Mtmr2-null neo and Mtmr2Fl/null ${ }^{\text {neo } / / P 0-~}$ Cre mice is less severe than human CMT4B1. To evaluate the possibility of a partial compensation by Mtm1, highly homologous to Mtmr2 and also expressed in myelin-forming Schwann cells (Bolino et al., 2004), we performed a quantitative expression analysis of Mtm $1 \mathrm{mRNA}$ in sci-

and axolemma in paranodal regions were in register and normally formed. Architecture of Schmidt-Lanterman incisures was preserved in longitudinal sections of Mtmr2-null ${ }^{\text {neo }}$ mouse nerves. To better evaluate the molecular organization of these regions in mutant nerves, we observed the distribution and staining intensity of E-cadherin, a known component of adherens atic nerve by RT-PCR. Mtm1 expression level was significantly increased in mutant nerves compared with controls (1.32-fold increase; $p<0.05$ ) (Fig. 9A). It has been reported that Mtm1 might heterodimerize in vitro with its catalytically inactive partner Mtmr12 (Nandurkar et al., 2003). To test the hypothesis that Mtm1 in the nerve might compensate loss of Mtmr2 only if 
Mtmr12 is also expressed, we first confirmed Mtmr12 expression in Schwann cells by qualitative RT-PCR analysis. Mtmr12 expression levels were then quantified, and no difference was observed between normal and mutant nerves (Fig. 9A). Levels of both Mtm1 and Mtmr12 mRNAs were also measured in other tissues, such as brain and muscle, which are not affected in CMT4B1. The expression levels of these two genes were similar in mutant and normal tissues, suggesting that the lack of phenotype in other tissues in which Mtmr2 is absent might not be attributable to functional compensation by Mtm1 (Fig. 9A).

Catalytically inactive MTMR5 interacts with MTMR2 in vitro (Kim et al., 2003). However, in vivo, the most likely interactor of MTMR2 in the nerve is the catalytically inactive protein MTMR13, because mutations in MTMR13 also cause CMT4B2 with myelin outfoldings. One might hypothesize that loss of Mtmr2 in mouse specifically affects Schwann cells and not other cell types because of the different tissue distribution of the two catalytically inactive partners Mtmr5 and Mtmr13. However, both genes were detected in muscle, brain, and nerve, and no significant changes in expression levels were appreciated between wild-type and mutant samples (Fig. 9A). The normal expression levels of Mtm1, Mtmr2, Mtmr5, Mtmr12, and Mtmr13 were also compared in the different tissues analyzed (Fig. 9B). In conclusion, we provide evidence that a significant increase of $M t m 1$ expression in Mtmr2-null ${ }^{\text {neo }}$ nerves might partially compensate loss of Mtmr2 in mouse Schwann cells.

\section{Discussion}

Mtmr2 conditional disruption in

Schwann cells but not in motor neurons provokes dysmyelination

We previously reported that Mtmr2 inactivation in mice reproduces CMT4B1 disease. Mtmr2-null ${ }^{\text {neo }}$ mice develop a dysmyelinating neuropathy with myelin outfoldings and infoldings, which arise (starting from 3-4 weeks after birth) at paranodal/ juxtaparanodal regions and at Schmidt-Lanterman incisures. Whether Schwann cells and/or neurons contribute to the dysmyelination remained to be assessed. A Schwann cell-autonomous role for Mtmr2 was suggested by the interaction between Mtmr2 and Dlg1/SAP97, a MAGUK (membrane associated guanilate kinase-like) protein specifically detected in the cytoplasm of both myelin-forming and nonmyelin-forming Schwann cells and not localized in axons (Bolino et al., 2004). In Mtmr2-null mouse nerves, Dlg1 staining at paranodal cytoplasm as well as at flanking incisures is almost lost. However, other evidence supports a cell autonomous role of Mtmr2 in neurons. Expression of Mtmr2 has been detected in vivo in axons, motor neurons, and sensory neurons. Also, we provided evidence that Mtmr2 might interact in
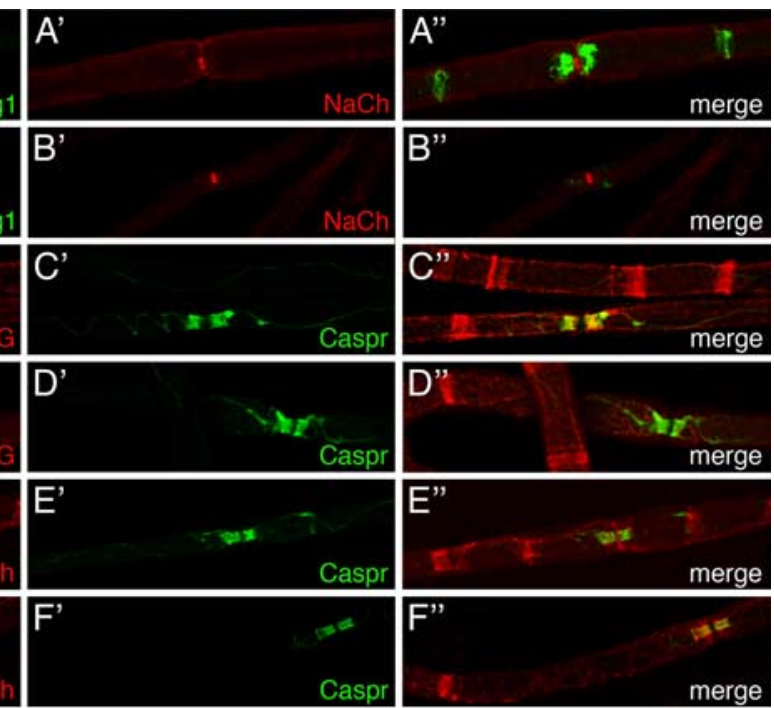

$\rightarrow$
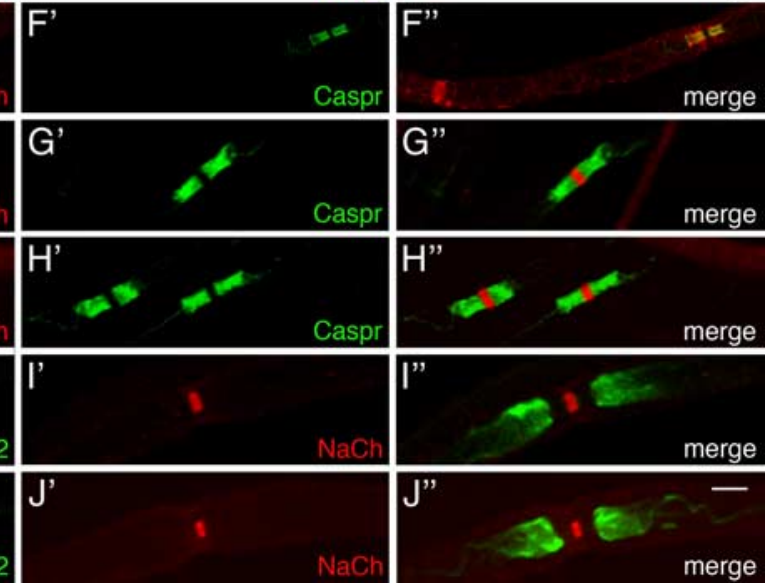

merge

Figure 7. Expression analysis of nodal, paranodal, and juxtaparanodal markers in Mtmr2-null ${ }^{\text {neo }}$ sciatic nerves. Immunohistochemistry was performed on teased fibers from Mtmr2-null ${ }^{\text {neo }}$ and normal sciatic nerves at 2 months of age. The following (green), which mark paranodal regions on the axomma, was performed $M A G$ staining is reduced in paranodes from nult compare the merge in ("' and D"). Reduced stainings of both DIg1 and MAG in Mtmr2-null neo fibers were further confirmed using 至 costained with $\mathrm{NaCh}$ (red) are shown. No difference in staining intensity or distribution of $\mathrm{NaCh}$, Caspr, and Kv1.1/1.2 clusters was appreciated between normal and mutant fibers. Scale bar: (in $\boldsymbol{J}^{\prime \prime}$ ) $\boldsymbol{A}-\boldsymbol{F}, 10 \mu \mathrm{m} ; \boldsymbol{G}-\boldsymbol{J}^{\prime \prime}, 5 \mu \mathrm{m}$.

neurons with NF-L, a protein mutated in either pure axonal forms of CMTs or in more severe forms with signs of primary demyelination (Jordanova et al., 2003; Previtali et al., 2003).

We now report the full characterization of two mouse models in which Mtmr2 was specifically disrupted in either Schwann cells or motor neurons. Mtmr2Fl/null ${ }^{\text {neo } / / P 0-C r e ~ m i c e ~ d e v e l o p ~ a ~ d y s-~}$ myelinating neuropathy very similar to that observed in Mtmr2null $^{\text {neo }}$ nerves. Myelin outfoldings arise at paranodal regions and at Schmidt-Lanterman incisures. The number of outfoldings increases with age, and the complexity progresses, being more pronounced at distal nerves. Occasional small onion bulbs were also noted at 12 and 15 months. In this model, it is interesting that even when Mtmr2 is ablated specifically in Schwann cells, axoplasm is found in the outfolds and recurrent loops of myelin. Thus, a primary genetic defect only in Schwann cells produces compensatory growth of axonal membrane. This may have a functional consequence. Although NaCh and Kv1.1/Kv1.2 clusters at nodal and juxtaparanodal regions, respectively, are not 
A

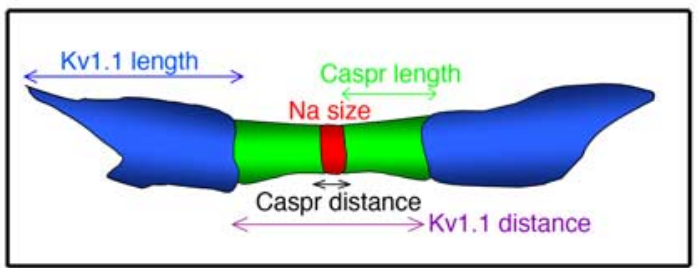

B

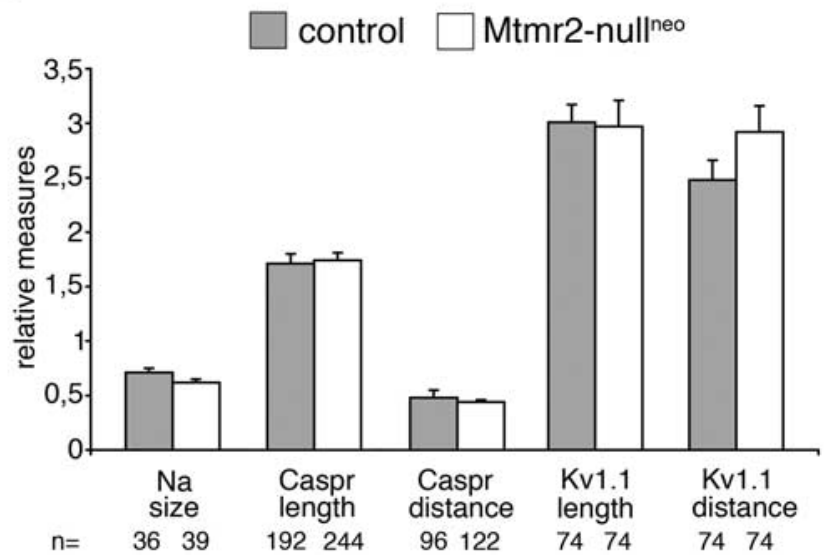

Figure 8. $\quad \boldsymbol{A}$, Analysis of protein clusters at nodal, paranodal, and juxtaparanodal regions of Mtmr2-null ${ }^{\text {neo }}$ sciatic nerves. $\boldsymbol{B}$, Na cluster size (wild type, $1.25 \pm 0.04 \mu \mathrm{m}$; knock-out, $1.46 \pm$ $0.04 \mu \mathrm{m}$ average) was normalized using the Na cluster diameter for each node (wild type, $1.85 \pm 0.05 \mu \mathrm{m}$; knock-out, $2.04 \pm 0.06 \mu \mathrm{m}$ average); $n$, Number of nodes analyzed. Caspr cluster length (wild type, $3.80 \pm 0.09 \mu \mathrm{m}$; knock-out, $4.06 \pm 0.09 \mu \mathrm{m}$ average) was normalized using Caspr diameter (wild type, $2.59 \pm 0.09 \mu \mathrm{m}$; knock-out, $2.57 \pm 0.07 \mu \mathrm{m}$ average). $n$ refers to paranodes analyzed. Kv1.1/1.2 cluster length (wild type, $8.22 \pm 0.47 \mu \mathrm{m}$; knockout, $6.91 \pm 0.40 \mu \mathrm{m}$ average) was normalized with the Na cluster diameter (wild type, $2.75 \pm$ $0.09 \mu \mathrm{m} ;$ knock-out, $2.48 \pm 0.11 \mu \mathrm{m}$ average). $n$ refers to juxtaparanodes analyzed. Kv1.1/1.2 cluster distance (wild type, $6.47 \pm 0.33 \mu \mathrm{m}$; knock-out, $6.54 \pm 0.29 \mu \mathrm{m}$ average) was normalized using $\mathrm{Na}$ cluster diameter as for Kv1.1/1.2 cluster length. $n$ is the number of fibers analyzed. The difference in Kv1.1/1.2 cluster distance between mutant and normal fibers was not statistically significant.

altered, a significant decrease in nerve conduction velocity $(\sim 19 \%)$ was demonstrated in Mtmr2-null ${ }^{\text {neo }}$ and Schwann cellnull mice. Axoplasm is found in most of the redundant loops observed in mutant nerves. It is possible that axonal branches will increase the capacitance, resulting in a decrease of the current spreading along the axon.

In contrast, $\mathrm{Mtmr} 2 \mathrm{Fl} /$ null $^{\text {neo }} / / \mathrm{HB} 9-\mathrm{Cre}$ mouse nerves did not show any sign of the CMT4B1 dysmyelinating neuropathy. These findings suggest that loss of Mtmr2 in Schwann cells is sufficient and necessary to generate myelin outfoldings.

Axonal defects were not noted in $\mathrm{Mtmr} 2 \mathrm{Fl} /$ null $^{\text {neo }} / / \mathrm{HB} 9-\mathrm{Cre}$ mouse nerves. Therefore, what is the role of Mtmr2 in motor neurons? Two scenarios might be envisaged. First, Mtmr2 could have no cell-autonomous role in these cells. In this case, the marked axonal loss observed in CMT4B1 patient nerves might be the consequence of the extensive demyelination and not the effect of a cell-autonomous role of the phosphatase in motor neurons. It has to be noted that, contrary to human CMTs, demyelination in mice does not necessarily result in marked axonal degeneration (Martini, 1997). In Mtmr2-null ${ }^{\text {neo }}$ mouse nerves, occasional small onion bulbs were noted only at 12-15 months of age. In both Mtmr2-null ${ }^{\text {neo }}$ and $M t m r 2 \mathrm{Fl} /$ null $^{\text {neo }} / / \mathrm{P} 0$-Cre but not in $\mathrm{Mtmr} 2 \mathrm{Fl} /$ null $^{\text {neo }} / / \mathrm{HB} 9-\mathrm{Cre}$, signs of axonal degeneration in sci-
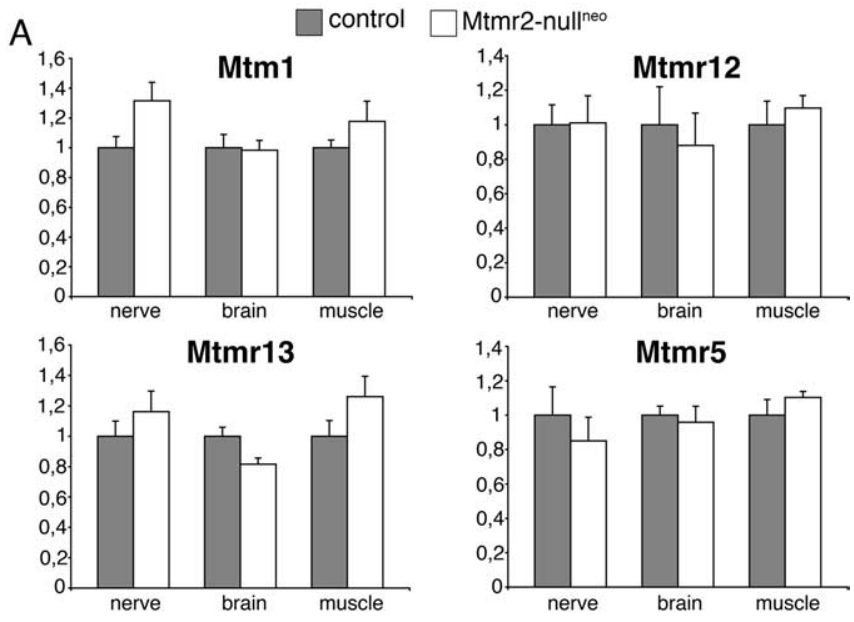

B
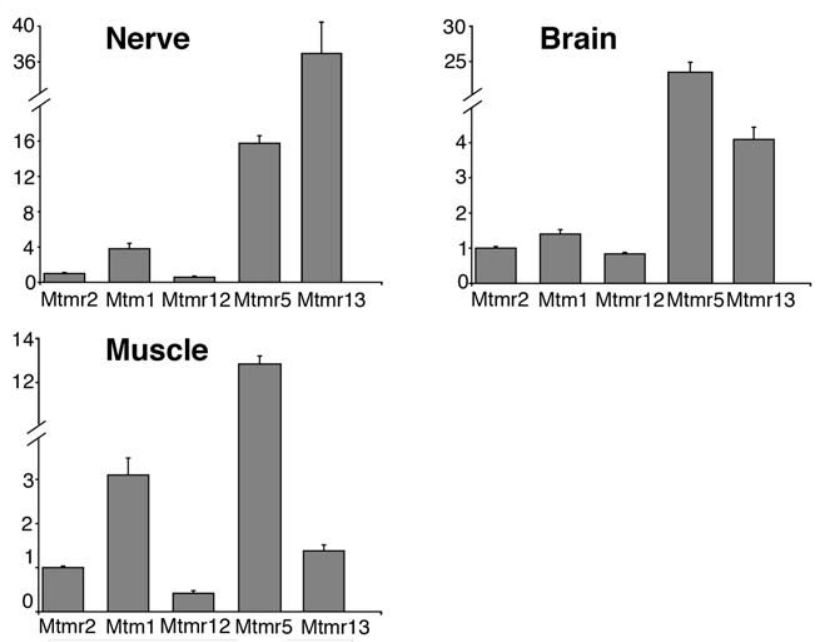

Figure 9. Expression analysis of MTMR family members. $A$, The expression of $M t m$ 1, Mtmr 12, Mtmr13, and Mtmr5 mRNAs was determined by RT-PCR in nerve, brain, and muscle from Mtmr2-null ${ }^{\text {neo }}$ and wild-type animals. TaqMan probes (Applied Biosystems) and the comparative $C_{T}$ method (ABI PRISM Sequence Detection System User Bulletin 2; Applied Biosystems) were used. mRNA expression levels ( $2^{-\Delta \Delta C T}$ values) in mutant tissues are indicated as $n$-folds with respect to the levels in normal tissues, taken as 1 . Diagrams show the average of expression levels calculated on at least three animals per genotype in muscle and brain and, for the nerve, on at least three separate pools of two animals each. SD was calculated for triplicate samples of each reaction, and SEM is indicated on the media of the determinations from different animals. B, mRNA expression levels of Mtmr2, Mtm1, Mtmr12, Mtmr5, and Mtmr13 in normal nerve, brain, and muscle. Mtm1, Mtmr12, Mtmr5, and Mtmr13 levels are indicated relative to Mtmr2, taken as 1 . The mRNA expression levels of different genes were compared at the same $C_{T}$ value, using the same endogenous references.

atic nerves were noted at an older age when a reduction of the number of myelinated fibers in more distal nerves was also revealed. Second, Mtmr2 has a cell-autonomous role in motor neurons in both humans and mice. The lack of axonal defects in the Mtmr2Fl/null neo//HB9-Cre mouse, which is generated by excision of exon 4 at E9.5, might suggest that other proteins are able to compensate Mtmr2 loss in motor neurons at this stage of development. Other possibilities might be that primary axonal neuropathies are not so easily reproducible in mice or that Mtmr2 function in motor neurons is related to particular physiological conditions of axons (for instance, after nerve injury), as reported previously for other proteins (Perlson et al., 2005). Additional experiments are necessary to test the latter hypothesis. 


\section{Alterations at sites of non-compact myelin}

Decreased levels of MAG and Dlg1 were initially demonstrated by Western blot analysis on Mtmr2-null ${ }^{\text {neo }}$ nerve homogenates. Consistently, immunohistochemical localization of MAG and Dlg1 on teased fibers demonstrated a reduction of MAG staining at paranodal regions. Dlg1 was almost absent from paranodes and flanking Schmidt-Lanterman incisures of null nerves. These molecular alterations suggest a defect at the level of non-compact myelin in which myelin outfoldings arise (at paranodal regions and incisures) in both mutants, Mtmr2-null ${ }^{\text {neo }}$, and Mtmr2Fl/ null $^{\text {neo } / / P 0-C r e . ~ E l e c t r o n ~ m i c r o s c o p y ~ r e v e a l e d ~ t h a t ~ t h e ~ g e n e r a l ~}$ architecture of these regions is preserved in these mice. This observation was also confirmed by immunohistochemical analysis of E-cadherin and Caspr, NaCh, and Kv1.1/Kv1.2 clusters. Quantitative RT-PCR analysis of MAG and Dlg1 mRNA levels did not show any difference between wild-type and mutant nerves (data not shown). Therefore, reduced protein synthesis, increased degradation, or altered recruitment to incisures and paranodal loops might be responsible for reduction of MAG and Dlg1 levels. Dlg1 interacts with Mtmr2 in Schwann cells and, therefore, when Mtmr2 is lost, it is also possible that Dlg1 is degraded. Whether the decreased level of MAG in null nerves is a consequence of the dysmyelination or whether it might be functionally related to the Mtmr2/Dlg1 complex remains to be assessed. A generalized defect in transport to Schmidt-Lanterman incisures or paranodal loops is not likely to occur, because other molecules located at paranodal regions (e.g., Caspr) were normally expressed and localized in mutant nerves.

Mtmr2 is a phospholipid phosphatase showing preferential activity toward PtdIns $3,5 \mathrm{P}_{2}$, a key regulator of vacuolar homeostasis and intracellular trafficking at the level of multivesicular bodies/late endosomes (Odorizzi et al., 1998). Dlg1/SAP97 is a component of adherens junctions in vertebrate epithelial cells, and it is involved in polarization, cell proliferation, and cancer (Humbert et al., 2003). In Schwann cells, Dlg1 is located at paranodal loops and Schmidt-Lanterman incisures in which several types of junctions are also located. Mtmr2/Dlg1 complex is disrupted in Schwann cells when Mtmr2 is absent. The pathogenesis of CMT4B1 is strictly related to the loss of Mtmr2/Dlg1 function in Schwann cells, perhaps involving membrane homeostasis/ vesicular trafficking targeted to adherens junctions of paranodes and incisures where myelin outfoldings arise. The finding that CMT4B1 neuropathy is caused by loss of Mtmr2 specifically in Schwann cells might help to specifically direct the efforts aimed at clarifying the molecular mechanism at the basis of this pathology. Moreover, therapeutical approaches based on the delivery of the Mtmr2 enzyme in Schwann cells of affected nerves might be designed.

\section{References}

Antonellis A, Ellsworth RE, Sambuughin N, Puls I, Abel A, Lee-Lin SQ, Jordanova A, Kremensky I, Christodoulou K, Middleton LT, Sivakumar K, Ionasescu V, Funalot B, Vance JM, Goldfarb LG, Fischbeck KH, Green ED (2003) Glycyl tRNA synthetase mutations in Charcot-Marie-Tooth disease type $2 \mathrm{D}$ and distal spinal muscular atrophy type V. Am J Hum Genet 72:1293-1299.

Arber S, Han B, Mendelsohn M, Smith M, Jessell TM, Sockanathan S (1999) Requirement for the homeobox gene HB9 in the consolidation of motor neuron identity. Neuron 23:659-674.

Azzedine H, Bolino A, Taieb T, Birouk N, Di Duca M, Bouhouche A, Benamou S, Mrabet A, Hammadouche T, Chkili T, Gouider R, Ravazzolo R, Brice A, Laporte J, LeGuern E (2003) Mutations in MTMR13, a new pseudophosphatase homologue of MTMR2 and Sbf1, in two families with an autosomal recessive demyelinating form of Charcot-Marie-Tooth dis- ease associated with early-onset glaucoma. Am J Hum Genet 72:1141-1153.

Bolino A, Muglia M, Conforti FL, LeGuern E, Salih MA, Georgiou DM, Christodoulou K, Hausmanowa-Petrusewicz I, Mandich P, Schenone A, Gambardella A, Bono F, Quattrone A, Devoto M, Monaco AP (2000) Charcot-Marie-Tooth type $4 \mathrm{~B}$ is caused by mutations in the gene encoding myotubularin-related protein-2. Nat Genet 25:17-19.

Bolino A, Marigo V, Ferrera F, Loader J, Romio L, Leoni A, Di Duca M, Cinti R, Cecchi C, Feltri ML, Wrabetz L, Ravazzolo R, Monaco AP (2002) Molecular characterization and expression analysis of Mtmr2, mouse homologue of MTMR2, the Myotubularin-related 2 gene, mutated in CMT4B. Gene 283:17-26.

Bolino A, Bolis A, Previtali SC, Dina G, Bussini S, Dati G, Amadio S, Del Carro U, Mruk DD, Feltri ML, Cheng CY, Quattrini A, Wrabetz L (2004) Disruption of Mtmr2 produces CMT4B1-like neuropathy with myelin outfolding and impaired spermatogenesis. J Cell Biol 167:711-721.

Bulfone A, Puelles L, Porteus MH, Frohman MA, Martin GR, Rubenstein JL (1993) Spatially restricted expression of Dlx-1, Dlx-2 (Tes-1), Gbx-2, and Wnt-3 in the embryonic day 12.5 mouse forebrain defines potential transverse and longitudinal segmental boundaries. J Neurosci 13:3155-3172.

Davis CJ, Bradley WG, Madrid R (1978) The peroneal muscular atrophy syndrome: clinical, genetic, electrophysiological and nerve biopsy studies. I. Clinical, genetic and electrophysiological findings and classification. J Genet Hum 26:311-349.

Evgrafov OV, Mersiyanova I, Irobi J, Van Den Bosch L, Dierick I, Leung CL, Schagina O, Verpoorten N, Van Impe K, Fedotov V, Dadali E, AuerGrumbach M, Windpassinger C, Wagner K, Mitrovic Z, Hilton-Jones D, Talbot K, Martin JJ, Vasserman N, Tverskaya S, et al. (2004) Mutant small heat-shock protein 27 causes axonal Charcot-Marie-Tooth disease and distal hereditary motor neuropathy. Nat Genet 36:602-606.

Fannon AM, Sherman DL, Ilyina-Gragerova G, Brophy PJ, Friedrich Jr VL, Colman DR (1995) Novel E-cadherin-mediated adhesion in peripheral nerve: Schwann cell architecture is stabilized by autotypic adherens junctions. J Cell Biol 129:189-202.

Feltri ML, D’Antonio M, Previtali S, Fasolini M, Messing A, Wrabetz L (1999) P0-Cre transgenic mice for inactivation of adhesion molecules in Schwann cells. Ann NY Acad Sci 883:116-123.

Feltri ML, Graus Porta D, Previtali SC, Nodari A, Migliavacca B, Cassetti A, Littlewood-Evans A, Reichardt LF, Messing A, Quattrini A, Mueller U, Wrabetz L (2002) Conditional disruption of beta 1 integrin in Schwann cells impedes interactions with axons. J Cell Biol 156:199-209.

Frei R, Motzing S, Kinkelin I, Schachner M, Koltzenburg M, Martini R (1999) Loss of distal axons and sensory Merkel cells and features indicative of muscle denervation in hindlimbs of P0-deficient mice. J Neurosci 19:6058-6067.

Humbert P, Russell S, Richardson H (2003) Dlg, Scribble and Lgl in cell polarity, cell proliferation and cancer. BioEssays 25:542-553.

Irobi J, Van Impe K, Seeman P, Jordanova A, Dierick I, Verpoorten N, Michalik A, De Vriendt E, Jacobs A, Van Gerwen V, Vennekens K, Mazanec R, Tournev I, Hilton-Jones D, Talbot K, Kremensky I, Van Den Bosch L, Robberecht W, Van Vandekerckhove J, Broeckhoven C, et al. (2004) Hot-spot residue in small heat-shock protein 22 causes distal motor neuropathy. Nat Genet 36:597-601.

Jessen KR, Mirsky R (2004) Schwann cell development. In: Myelin biology and disorders (Lazzarini RA, Griffin JW, Lassman H, Nave K-A, Miller RH, Trapp BD, eds), pp 329-354. San Diego: Elselvier Academic.

Jordanova A, De Jonghe P, Boerkoel CF, Takashima H, De Vriendt E, Ceuterick C, Martin JJ, Butler IJ, Mancias P, Papasozomenos S, Terespolsky D, Potocki L, Brown CW, Shy M, Rita DA, Tournev I, Kremensky I, Lupski JR, Timmerman V (2003) Mutations in the neurofilament light chain gene (NEFL) cause early onset severe Charcot-Marie-Tooth disease. Brain 126:590-597.

Kim SA, Vacratsis PO, Firestein R, Cleary ML, Dixon JE (2003) Regulation of myotubularin-related (MTMR)2 phosphatidylinositol phosphatase by MTMR5, catalytically inactive phosphatase. Proc Natl Acad Sci USA 100: 4492-4497.

Laporte J, Bedez F, Bolino A, Mandel JL (2003) Myotubularins, a large disease-associated family of cooperating catalytically active and inactive phosphoinositides phosphatases. Hum Mol Genet 12:R285-R292.

Lappe-Siefke C, Goebbels S, Gravel M, Nicksch E, Lee J, Braun PE, Griffiths 
IR, Nave KA (2003) Disruption of Cnp1 uncouples oligodendroglial functions in axonal support and myelination. Nat Genet 33:366-374.

Li H, Arber S, Jessell TM, Edlund H (1999) Selective agenesis of the dorsal pancreas in mice lacking homeobox gene Hlxb9. Nat Genet 23:67-70.

Martini R (1997) Animal models for inherited peripheral neuropathies. J Anat 191:321-336.

Michailov GV, Sereda MW, Brinkmann BG, Fischer TM, Haug B, Birchmeier C, Role L, Lai C, Schwab MH, Nave KA (2004) Axonal neuregulin-1 regulates myelin sheath thickness. Science 304:700-703.

Nandurkar HH, Layton M, Laporte J, Selan C, Corcoran L, Caldwell KK, Mochizuki Y, Majerus PW, Mitchell CA (2003) Identification of myotubularin as the lipid phosphatase catalytic subunit associated with the 3-phosphatase adapter protein, 3-PAP. Proc Natl Acad Sci USA 100:8660-8665.

Odorizzi G, Babst M, Emr SD (1998) Fablp PtdIns(3)P 5-kinase function essential for protein sorting in the multivesicular body. Cell 95:847-858.

Pedrola L, Espert A, Wu X, Claramunt R, Shy ME, Palau F (2005) GDAP1, the protein causing Charcot-Marie-Tooth disease type $4 \mathrm{~A}$, is expressed in neurons and is associated with mitochondria. Hum Mol Genet 14:1087-1094.

Perlson E, Hanz S, Ben-Yaakov K, Segal-Ruder Y, Seger R, Fainzilber M (2005) Vimentin-dependent spatial translocation of an activated MAP kinase in injured nerve. Neuron 45:715-726.

Poliak S, Peles E (2003) The local differentiation of myelinated axons at nodes of Ranvier. Nat Rev Neurosci 4:968-980.

Previtali SC, Quattrini A, Fasolini M, Panzeri MC, Villa A, Filbin MT, Li W, Chiu SY, Messing A, Wrabetz L, Feltri ML (2000) Epitope-tagged P(0) glycoprotein causes Charcot-Marie-Tooth-like neuropathy in transgenic mice. J Cell Biol 151:1035-1046.

Previtali SC, Zerega B, Sherman DL, Brophy PJ, Dina G, King RH, Salih MM, Feltri L, Quattrini A, Ravazzolo R, Wrabetz L, Monaco AP, Bolino A (2003) Myotubularin-related 2 protein phosphatase and neurofilament light chain protein, both mutated in CMT neuropathies, interact in peripheral nerve. Hum Mol Genet 12:1713-1723.

Quattrone A, Gambardella A, Bono F, Aguglia U, Bolino A, Bruni AC, Montesi MP, Oliveri RL, Sabatelli M, Tamburrini O, Valentino P, Van Broeckhoven C, Zappia M (1996) Autosomal recessive hereditary motor and sensory neuropathy with focally folded myelin sheaths: clinical, electrophysiologic, and genetic aspects of a large family. Neurology 46:1318-1324.

Rouger H, LeGuern E, Birouk N, Gouider R, Tardieu S, Plassart E, Gugenheim M, Vallat JM, Louboutin JP, Bouche P, Agid Y, Brice A (1997) Charcot-Marie-Tooth disease with intermediate motor nerve conduction velocities: characterization of $14 \mathrm{Cx} 32$ mutations in 35 families. Hum Mutat 10:443-452.

Salzer JL (2003) Polarized domains of myelinated axons. Neuron 40:297-318.

Schaletzky J, Dove SK, Short B, Lorenzo O, Clague MJ, Barr FA (2003) Phosphatidylinositol-5-phosphate activation and conserved substrate specificity of the myotubularin phosphatidylinositol 3-phosphatases. Curr Biol 13:504-509.

Senderek J, Bergmann C, Weber S, Ketelsen UP, Schorle H, RudnikSchoneborn S, Buttner R, Buchheim E, Zerres K (2003) Mutation of the SBF2 gene, encoding a novel member of the myotubularin family, in Charcot-Marie-Tooth neuropathy type 4B2/11p15. Hum Mol Genet $12: 349-356$.

Shy ME (2004) Charcot-Marie-Tooth disease: an update. Curr Opin Neurol 17:579-585.

Suter U, Scherer SS (2003) Disease mechanisms in inherited neuropathies. Nat Rev Neurosci 4:714-726.

Trapp BD, Kidd GJ (2004) Structure of the myelinated axon. In: Myelin biology and disorders (Lazzarini RA, Griffin JW, Lassman H, Nave K-A, Miller RH, Trapp BD, eds), pp 3-27. San Diego: Elsevier Academic.

Verhoeven K, De Jonghe P, Coen K, Verpoorten N, Auer-Grumbach M, Kwon JM, FitzPatrick D, Schmedding E, De Vriendt E, Jacobs A, Van Gerwen V, Wagner K, Hartung HP, Timmerman V (2003) Mutations in the small GTP-ase late endosomal protein RAB7 cause Charcot-MarieTooth type 2B neuropathy. Am J Hum Genet 72:722-727.

Wrabetz L, Feltri ML, Quattrini A, Imperiale D, Previtali S, D'Antonio M, Martini R, Yin X, Trapp BD, Zhou L, Chiu SY, Messing A (2000) P(0) glycoprotein overexpression causes congenital hypomyelination of peripheral nerves. J Cell Biol 148:1021-1034.

Wrabetz L, Feltri ML, Kleopa KA, Scherer S (2004) Inherited neuropathies: clinical, genetic, and biological features. In: Myelin biology and disorders (Lazzarini RA, Griffin JW, Lassman H, Nave K-A, Miller RH, Trapp BD, eds), pp 905-951. San Diego: Elsevier Academic.

Yang X, Arber S, William C, Li L, Tanabe Y, Jessell TM, Birchmeier C, Burden SJ (2001) Patterning of muscle acetylcholine receptor gene expression in the absence of motor innervation. Neuron 30:399-410.

Zuchner S, Mersiyanova IV, Muglia M, Bissar-Tadmouri N, Rochelle J, Dadali EL, Zappia M, Nelis E, Patitucci A, Senderek J, Parman Y, Evgrafov O, Jonghe PD, Takahashi Y, Tsuji S, Pericak-Vance MA, Quattrone A, Battaloglu E, Polyakov AV, Timmerman V, et al. (2004) Mutations in the mitochondrial GTPase mitofusin 2 cause Charcot-Marie-Tooth neuropathy type 2A. Nat Genet 36:449-451. 